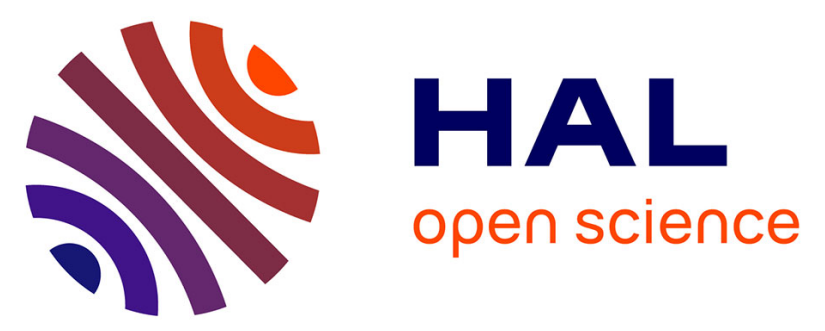

\title{
Single-Photon, Double Photodetachment of Nickel Phthalocyanine Tetrasulfonic Acid 4-Anions
}

Steven Daly, Marion Girod, Marin Vojkovic, Alexandre Giuliani, Rodolphe Antoine, Laurent Nahon, Richard A.J. O'Hair, P Dugourd

\section{- To cite this version:}

Steven Daly, Marion Girod, Marin Vojkovic, Alexandre Giuliani, Rodolphe Antoine, et al.. SinglePhoton, Double Photodetachment of Nickel Phthalocyanine Tetrasulfonic Acid 4-Anions. Journal of Physical Chemistry Letters, 2016, 7 (13), pp.2586-2590. 10.1021/acs.jpclett.6b01030 . hal-01344589

\author{
HAL Id: hal-01344589 \\ https://hal.science/hal-01344589
}

Submitted on 12 Jul 2016

HAL is a multi-disciplinary open access archive for the deposit and dissemination of scientific research documents, whether they are published or not. The documents may come from teaching and research institutions in France or abroad, or from public or private research centers.
L'archive ouverte pluridisciplinaire HAL, est destinée au dépôt et à la diffusion de documents scientifiques de niveau recherche, publiés ou non, émanant des établissements d'enseignement et de recherche français ou étrangers, des laboratoires publics ou privés. 
Single-Photon, Double Photodetachment of Nickel Phthalocyanine Tetrasulfonic Acid 4- Anions. S. Daly, M. Girod, M. vojkovic, A. Giuliani, R. Antoine, L. Nahon, R. A. J. O'Hair and P. Dugourd. J. Phys. Chem. Lett. (2016). http://dx.doi.org/10.1021/acs.jpclett.6b01030 


\section{Single-Photon, Double Photodetachment of Nickel}

\section{Phthalocyanine Tetrasulfonic Acid 4- Anions.}

Steven Daly, ${ }^{a}$ Marion Girod, ${ }^{b}$ Marin Vojkovic, ${ }^{a}$ Alexandre Giuliani, ${ }^{c, d}$ Rodolphe Antoine, ${ }^{a}$ Laurent Nahon, ${ }^{c}$ Richard A. J. O'Hair ${ }^{e, f}$ and Philippe Dugourd, ${ }^{\ddagger a}$

a Institut Lumière Matière, Université Claude Bernard Lyon 1, CNRS UMR 5306, Lyon, France.

${ }^{\mathrm{b}}$ Institut des Sciences Analytiques, Université de Lyon, Université Claude Bernard Lyon 1, CNRS \& ENS Lyon, UMR 5280, 69100 Villeurbanne, France.

${ }^{\text {c }}$ SOLEIL, l'Orme des Merisiers, St Aubin, BP48, F-91192 Gif sur Yvette

Cedex, France

d INRA, UAR1008 Caractérisation et Élaboration des Produits Issus de l'Agriculture, F-44316 Nantes, France

${ }^{\mathrm{e}}$ School of Chemistry and Bio21 Molecular Science and Biotechnology Institute, University of Melbourne, 30 Flemington Rd, Parkville, Victoria 3010, Australia.

${ }^{\mathrm{f}}$ ARC Centre of Excellence for Free Radical Chemistry and Biotechnology. 
Single-photon, two-electron photodetachment from nickel phthalocyanine tetrasulfonic acid tetra anions, $\mathrm{NiPc}^{4-}$, was examined in the gas-phase using a linear ion trap coupled to the DESIRS VUV beamline of the SOLEIL Synchrotron. This system was chosen since it has a low detachment energy, known charge localization, and well defined geometrical and electronic structures. A threshold for two-electron loss is observed at $10.2 \mathrm{eV}$, around $1 \mathrm{eV}$ lower than previously observed double detachment thresholds on multiple charged protein anions. The photodetachment energy of $[\mathrm{NiPc}]^{4-}$ has been previously determined to be $3.5 \mathrm{eV}$ and the photodetachment energy of $[\mathrm{NiPc}]^{3-\bullet}$ is determined in this work to be $4.3 \mathrm{eV}$. The observed single photon double electron detachment threshold is hence $5.9 \mathrm{eV}$ higher than the energy required for sequential single electron loss. Possible mechanisms are for double photodetachment are discussed. These observations pave the way toward new, exciting experiments for probing double photodetachment at relatively low energies, including correlation measurements on emitted photoelectrons.

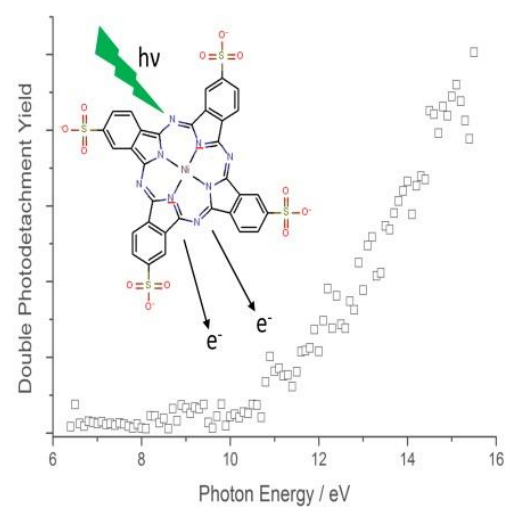


The detachment of two electrons from a gas-phase species via the absorption of a single photon is a common process that is observed in systems as diverse as neutral or charged atoms, small molecules, molecular anions and multiply charged proteins (Table 1) ${ }^{1-13}$. A range of mechanisms for double electron detachment are available, including processes such Auger emission, shake-off processes, knock-out and relaxation following double excitation. In the case of multiply deprotonated proteins, the detachment of two electrons was found to be essentially independent of the charge state or size of the system, possessing an onset of $\sim 11.2$ $\mathrm{eV}$ across a diverse range of systems. However, due to the large size of proteins and a range of possible deprotonation sites, it is difficult to precisely identify the mechanism leading to 
the single photon double electron detachment. It was, however, noted that $11.2 \mathrm{eV}$ corresponds to the ionization energy of neutral tryptophan plus the electron affinity of the carboxylate (i.e. deprotonated carboxylic acid group), and that the onset of triple detachment required an additional $3.6 \mathrm{eV}$, which corresponds to the electron affinity of another carboxylate.

Table 1: Examples of one photon double electron loss processes described in the literature in which mass spectrometry (MS) is used to either select and/or detect ions.

\begin{tabular}{|l|l|l|l|l|l|}
\hline $\begin{array}{l}\text { Reactant } \\
\text { species }\end{array}$ & $\begin{array}{l}\text { Selected via } \\
\text { MS? }\end{array}$ & $\begin{array}{l}\text { Energy } \\
\text { Range } / \mathrm{eV}\end{array}$ & $\begin{array}{l}\text { Detected } \\
\text { via MS? }\end{array}$ & Examples & REF \\
\hline $\mathrm{M}^{\mathrm{n}+}$ & yes & $>250$ & yes $^{(\mathrm{a})}$ & Multiply protonated proteins & {$[1]$} \\
\hline $\mathrm{M}^{+}$ & yes & $>100$ & yes $^{(\mathrm{a})}$ & Clusters & {$[2]$} \\
\hline $\mathrm{M}$ & no & $>17$ & yes & Atoms, small molecules, fullerenes & {$[3-7]$} \\
\hline $\mathrm{M}^{-}$ & yes & $>15$ & yes $^{(\mathrm{b})}$ & $\mathrm{Li}^{-}, \mathrm{F}^{-}, \mathrm{CN}^{-}, \mathrm{C}_{60}-$ & {$[8-10]$} \\
\hline $\mathrm{M}^{2-}$ & yes & $\mathrm{M}$ & no & Coinage metal clusters & {$[11]$} \\
\hline $\mathrm{M}^{\mathrm{n}-}$ & yes & $>11.4$ & yes & Multiply deprotonated proteins & {$[12,13]$} \\
\hline
\end{tabular}

(a) this channel requires a high energy photon ( $2 x$ ionization energy).

(b) this channel is called "charge reversal".

(c) this channel is inferred from signal loss.

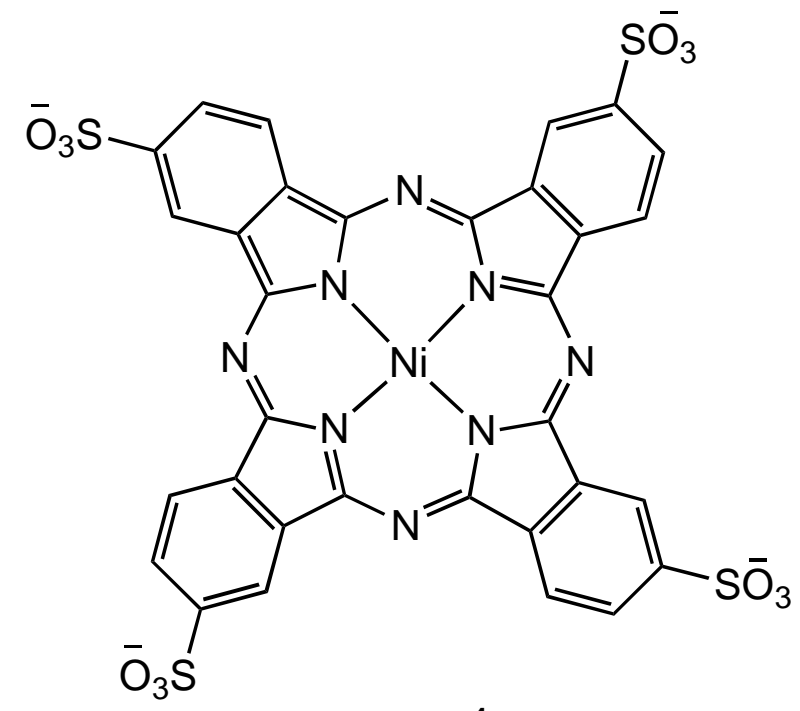

$[\mathrm{NiPc}]^{4-}$

Scheme 1. The structure of the tetra-anion of Nickel Phthalocyanine tetrasulfonic acid. 
Given that the folded structures and the location of the anionic sites in multiply deprotonated proteins are difficult to quantify, it is desirable to study a multiply charged anion (MCA) whose molecular architecture and electronic structure is well defined. The metal phthalocyanine tetrasulfonic acids (MPc) are amongst the smallest MCAs ${ }^{14-16}$ that meet these requirements and that can be transferred to the gas phase via electrospray ionization (ESI). As compared to previously studied MCAs, the excess electrons are localized on specific, spatially well-defined sites (see Scheme 1). Furthermore, spectroscopic data for photodetachment is already available; the gas-phase photoelectron spectroscopy of MPc MCAs has been studied by both the Wang ${ }^{17,18}$ and Kappes ${ }^{19,20}$ groups. It was found that the 4- charge states of CuPc and $\mathrm{NiPc}$ possessed a negative electron binding energy and were in fact metastable due to the presence of a Repulsive Coulomb Barrier (RCB). The MPc systems therefore represent the perfect candidates to study one photon two electron photodetachment at low energy. Here we use linear ion trap mass spectrometers coupled to either an OPO laser ${ }^{21}$ or a vacuum UV line of SOLEIL 22,23 to explore the photodetachment of the $4-$ and 3-• charge states of NiPc (Scheme 1) with either UV or VUV light in an effort to characterize the one-photon twoelectron photodetachment process.

The photochemistry of $[\mathrm{NiPc}]^{4-}$ is rich and involves both photofragmentation and photodetachment (see for example reference 24 and Figures S1-3 and Tables S1-2). The photodetachment yields of $[\mathrm{NiPc}]^{4-}$ in the VUV are shown in Figure 1(a) for 1 electron loss, while that for 2 electron loss is shown in Figure 1(b). 


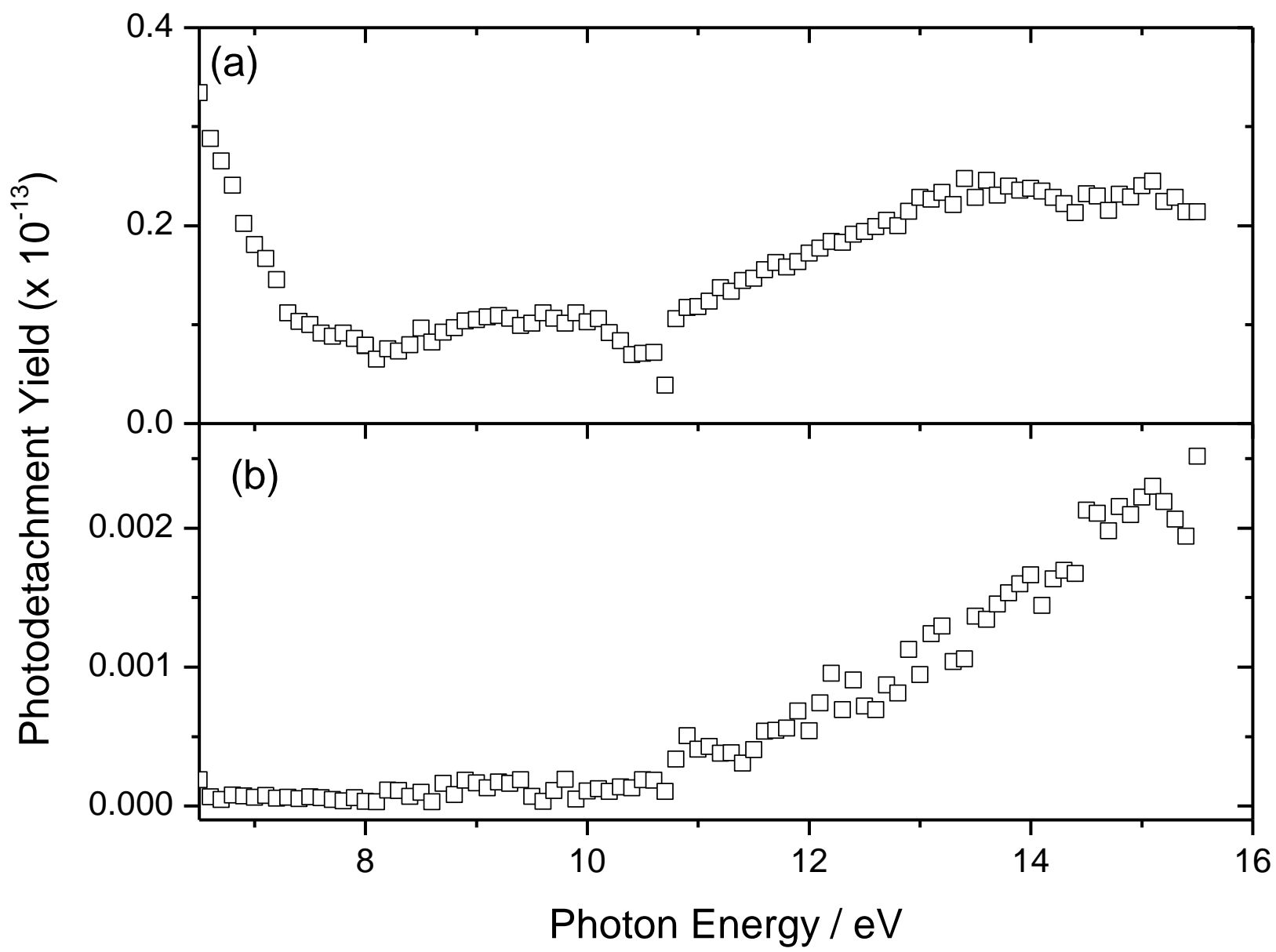

Figure 1. Photodetachment yields of $[\mathrm{NiPc}]^{4-}$ in the VUV: (a) 1 electron loss and (b) 2 electron loss. An onset of $10.2 \mathrm{eV}$ is observed in for the double electron loss process along with a feature in the single electron loss yield.

A similar trend in the photodetachment yields is observed, which increase at photon energies above $10 \mathrm{eV}$, with an onset observed at a photon energy of $10.2 \mathrm{eV}$ for 2 electron loss (see Figure S4). Since thermal electron loss from the metastable $[\mathrm{NiPc}]^{4-}$ anion is observed on the experimental timescale, fitting a threshold for 1 electron loss is not possible as it relies on a smooth baseline. Nevertheless, there is a clear feature in the photodetechment yield which appears to be concurrent with the onset observed in the two electron loss channel (see Figure S5).

In order to establish whether there is direct two electron loss or if sequential electron losses occurs via absorption of two individual photons, the dependence of the single and double photodetachment yields were monitored as a function of the irradiation time at 7, 9 and $15 \mathrm{eV}$ 
- Figure 2. For all photon energies it is clear that single photodetachment has a linear dependence on the irradiation time, indicating the expected single photon process. In the case of double electron loss, the dependence is clearly quadratic for 7 and $9 \mathrm{eV}$ - both of which are below the onset of $10.2 \mathrm{eV}$ - indicating a sequential two photon process. At $15 \mathrm{eV}$, the dependence of double detachment on irradiation - whilst still containing a trace of quadratic and hence two photon sequential detachment - is clearly much more linear than below the observed double detachment threshold and hence this threshold can be attributed to be predominantly a direct, single photon double electron detachment phenomenon (see Figure S6). A noteworthy difference is that the yield for 1 electron loss is around 2 orders of magnitude greater than 2 electron loss. Furthermore, the fact that the observed 1 and 2 electron loss channels share similar features in the VUV above $10 \mathrm{eV}$ (Figure 1) may indicate that these two processes represent different relaxation pathways of the same initial excitation.
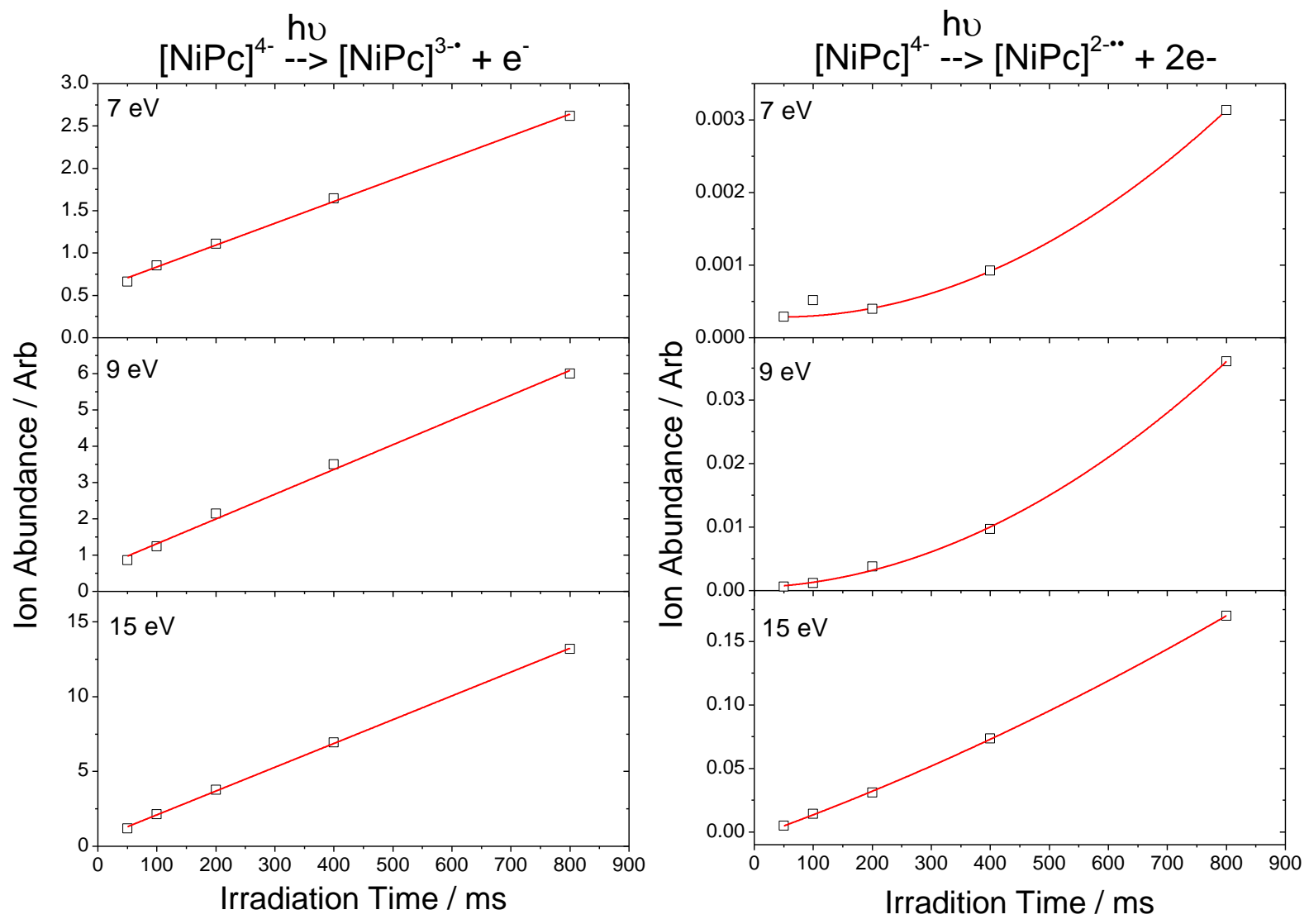

Figure 2. Single (left) and double (right) photodetachment yields as a function of the irradiation time at $7 \mathrm{eV}$ (top), $9 \mathrm{eV}$ (middle) and $15 \mathrm{eV}$ (bottom). 
The onset of 2 electron loss in $[\mathrm{NiPc}]^{4-}$ is about $1 \mathrm{eV}$ lower than previously observed double detachment thresholds of multiple charged protein anions ${ }^{13,25}$, and as far as we are aware represents a new record for the lowest value for single photon, double detachment in the gas phase of any species. In the protein polyanion case, it was noted that there was a correlation with the ionization energy for the tryptophan side chain plus the detachment energy of the carboxylate anion, suggesting a possible mechanism in which 1 electron is removed from the tryptophan side chain and the other from the carboxylate, but without any footprint for how the two electrons are correlated. For $[\mathrm{NiPc}]^{4-}$, the compact structure and well-defined charge location facilitates comprehension of how the emitted electrons may be correlated.

There are, in general, four possible mechanisms for the loss of two electrons following absorption of a single photon: (i) Auger-like processes whereby removal of a core electron causes emission of a second electron during relaxation; (ii) direct processes where double electron excitation leads directly to emission of two electrons; (iii) shake-off processes where the detachment of the first electron leaves the charge-reduced molecule in an excited state that can relax by emitting a second electron; and (iv) knockout processes where the kinetic energy of the outgoing photoelectron can be transferred to a second electron, causing it to be emitted as well. 


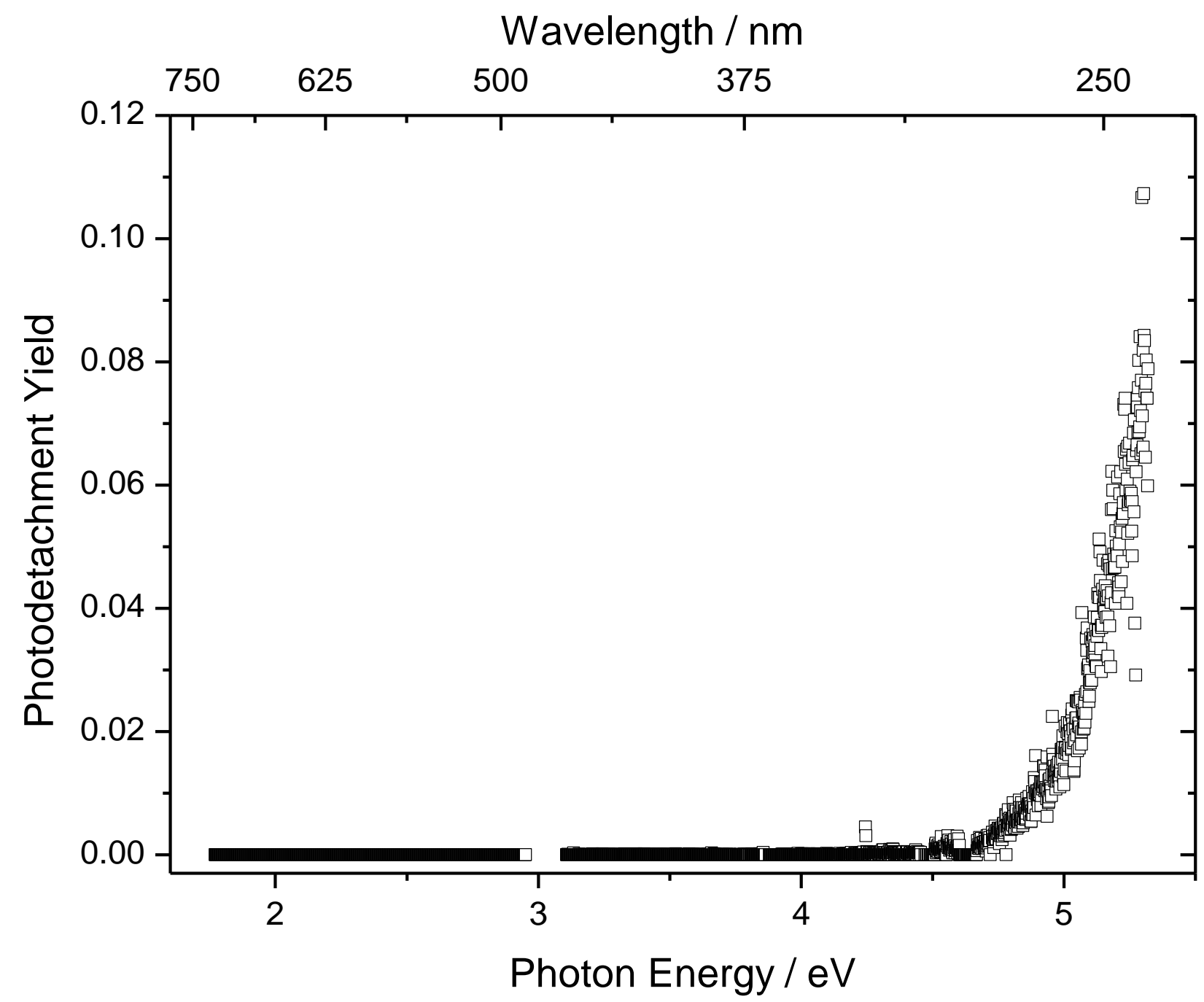

Figure 3. Photodetachment yield of $[\mathrm{NiPc}]^{3-\bullet} \rightarrow[\mathrm{NiPC}]^{2-\bullet}+\mathrm{e}^{-}$in the range 1.78 to $5.5 \mathrm{eV}$.

To better quantify the lower limits for the energetics associated with 2 electron loss from $[\mathrm{NiPc}]^{4-}$, it is important to know the energy for sequential single electron loss. The photoelectron spectroscopy for single electron loss from $[\mathrm{NiPc}]^{4-}$ has been reported ${ }^{26}$. Although $[\mathrm{NiPc}]^{3-\bullet}$ has a negative electron affinity $(-0.65 \mathrm{eV})$, there is a $\mathrm{RCB}$, which costs 3.5 $\mathrm{eV}$ to be surmounted. The missing piece of information is the energy required to remove an electron from $[\mathrm{NiPc}]^{3-\bullet}$. Thus we have measured the photodetachment spectrum of $[\mathrm{NiPc}]^{3-\bullet}$ between 1.8 and $5.5 \mathrm{eV}$ (Figure 3), with an onset of $4.3 \mathrm{eV}$ observed (see Figure S7). This value may be used in conjunction with the height of the RCB of $[\mathrm{NiPc}]^{4-}$ to construct a diagram for the energetics of photodetachment (Figure 4). Although the relative energy of 
$[\mathrm{NiPc}]^{2-*}$ is not known, it is not relevant to the discussion of double electron loss from $[\mathrm{NiPc}]^{4-}$ and an arbitrary value is assumed in Figure 4.

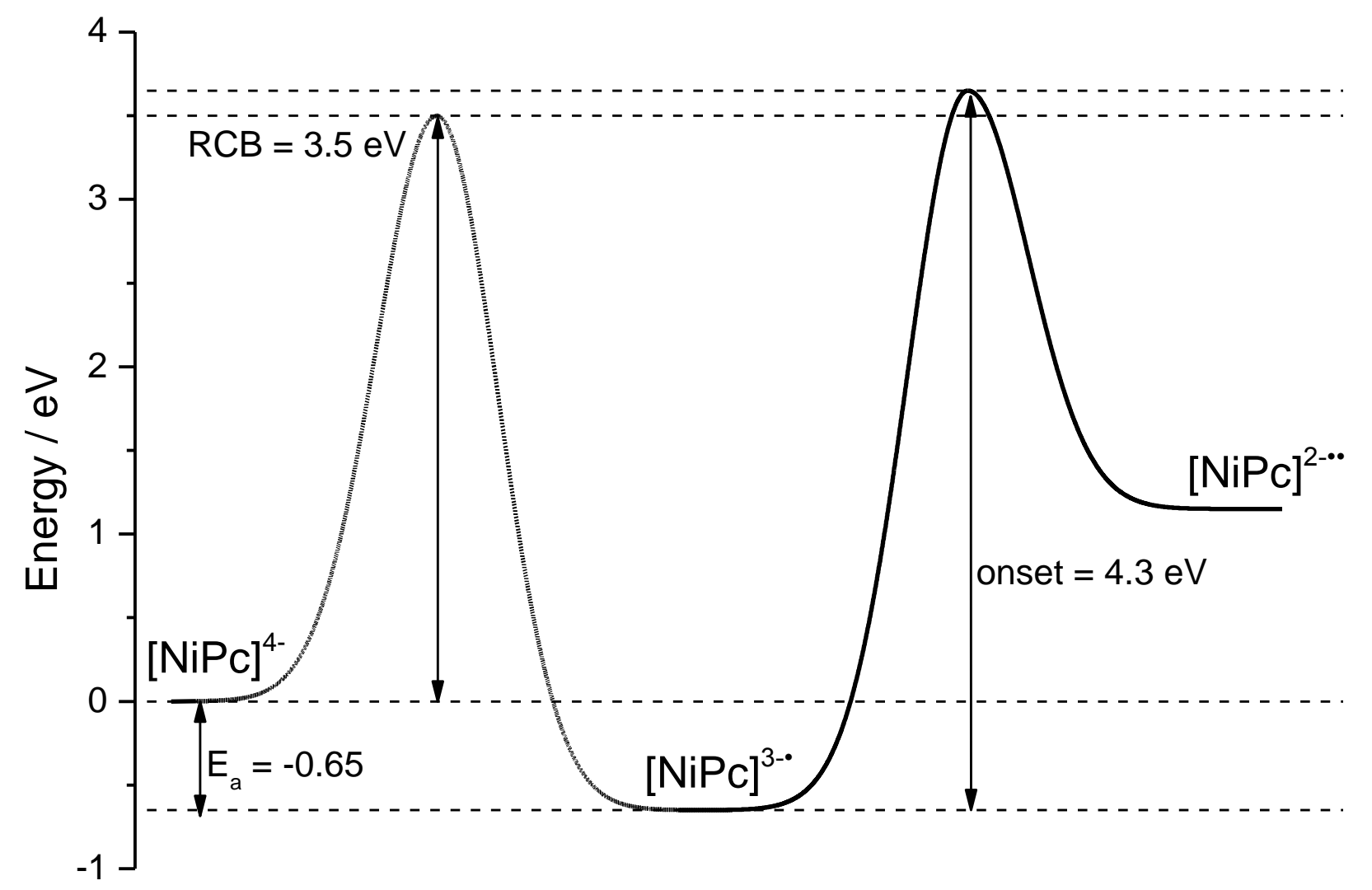

Figure 4. Schematic diagram showing the relative energetics for removal of an electron from either $[\mathrm{NiPc}]^{4-}$ or $[\mathrm{NiPc}]^{3-\bullet}$. The $\mathrm{RCB}$ for $[\mathrm{NiPc}]^{4-}$ and the relative energy of $[\mathrm{NiPc}]^{4-}$ and $[\mathrm{NiPc}]^{3-\bullet}$ are taken from references ${ }^{19,20}$. The value for $[\mathrm{NiPc}]^{3-\bullet}$ is taken from the electron detachment onset of this species shown in Figure 3.

The threshold for sequential two photon detachment is $4.3 \mathrm{eV}$, corresponding to the onset of photodetachment of $[\mathrm{NiPc}]^{3 \cdot \bullet}$, the largest barrier which must be surmounted (absorption of 2 photons of $\left.4.3 \mathrm{eV} ;[\mathrm{NiPc}]^{4-} \rightarrow[\mathrm{NiPC}]^{3-\bullet} \rightarrow[\mathrm{NiPc}]^{2-\bullet}\right)$. This process has already been eliminated by the linearity of double photodetachment in Figure 2. Auger-type relaxation channels are typically not open in the VUV region, with photon energies of at least $25 \mathrm{eV}$ generally being required ${ }^{8}$ and thus may be discounted as the mechanism responsible for 2 electron detachment here. In the knock-out process, the electron kinetic energy of the photoelectron is responsible for removal of the second electron. Hence, the threshold energy for this channel is the sum of the binding energies of the two electrons removed. In the case of 
$[\mathrm{NiPc}]^{4-}$ the situation is complicated by the negative binding energy relative to the $[\mathrm{NiPc}]^{3-\bullet}$ and the RCB. A photoelectron emitted after absorption of a photon of $3.5 \mathrm{eV}$ (i.e. just above the $\mathrm{RCB}$ ) will have a maximum kinetic energy of $4.15 \mathrm{eV}$ due to the $-0.65 \mathrm{eV}$ binding energy. Since the onset for photodetachment of $[\mathrm{NiPc}]^{3-\bullet}$ is $4.3 \mathrm{eV}$, a $3.65 \mathrm{eV}$ photon is all that is required for the photoelectron emitted from $[\mathrm{NiPc}]^{4-}$ to have sufficient kinetic energy to remove an electron from $[\mathrm{NiPc}]^{3-\bullet}$. This is $6.55 \mathrm{eV}$ lower than the observed threshold, which would appear to exclude this mechanism of two electron detachment. It has been previously shown that the first electron removed from $[\mathrm{NiPc}]^{4-}$ comes from the $\pi$ system of the phthalocyanine ${ }^{24}$. Given that this electron is corralled by the sulfonates, the electron will preferentially leave the system in the out-of-plane directions. Such an asymmetry in the angle of photoemission would minimize the potential interaction with other electrons in the system, and in particular with the electrons in the negatively charge sulfonate group. It is thus reasonable to exclude knock-out type mechanisms as the origin of two electron loss in $[\mathrm{NiPc}]^{4-}$.

This, therefore, leaves the direct double detachment and shake-off processes as possible mechanisms. Both are consistent with the observed onsets of 1 and 2 electron detachment, and both are non-resonant processes based upon electron correlation. There is evidence for relatively intense double photoionization processes in aromatic hydrocarbons with He-like energy trends and depending in magnitude of the molecules ${ }^{27}$. Shake-off ionization can be described as a sudden change in the potential after ionization of the first electron, who can relax by ejection of a second electron. ${ }^{30}$ This has likewise been shown to be important in small molecules, and may dominate at threshold where knock-out processes are absent (as they appear to be here $)^{28,29}$. Considering the very low electron binding energy in polyanions, as compared to neutrals, shake-off processes may be expected to be quite efficient. Although there is evidence of electron correlation in the observation of linked single and double 
electron detachment channel yields, there is no information on the relative energetics of the two electrons, or the timescale of their emission. In particular for a correlated double electronic excitation leading to concerted double photoemission, electrons with the similar kinetic energy are expected whilst for shake-off two different kinetic energy photoelectrons may be expected. Disentangling these two channels would require use of a photoelectronphotoelectron coincidence (PEPECO) experiment in order to measure the photoelectron kinetic energies and especially the energy sharing between the two outgoing electrons as it is regularly performed on neutrals ${ }^{4,31}$. To our knowledge such a PEPECO scheme has never been applied to trapped ions.

In summary, the single and double electron detachment from $[\mathrm{NiPc}]^{4-}$ has been studied using a combination of laser- and synchrotron-based spectroscopy in a linear ion trap. An onset of $10.2 \mathrm{eV}$ was found for double electron detachment, which is the lowest currently observed threshold for one-photon double detachment. The measurement of the double detachment yield as function of the irradiation time showed a predominately linear trend above this threshold, which eliminates sequential photon absorption as a mechanism. In order to quantify the energetics of sequential electron detachment after absorption of two photons, the photodetachment of $[\mathrm{NiPc}]^{3-\bullet}$ was measured between 1.8 and $5.5 \mathrm{eV}$, with an onset of $4.3 \mathrm{eV}$ observed. The well-defined geometry of the molecule has allowed a detailed spectroscopic characterization to be performed, allowing an evaluation of potential mechanisms for onephoton two-electron loss from a consideration of all relevant energetics. Auger- and knockout processes were discounted, suggesting that direct detachment following double excitation is the most likely mechanism leading to double photodetachment. This argument is strengthened by similarities of the VUV features for single and double electron detachment yields above $10 \mathrm{eV}$ (Figure 1). Observation of one-photon two-electron emission at $10.2 \mathrm{eV}$ opens up the prospect of studying high energy ionization processes at rather low excitation 
energies (in the VUV), where detailed spectroscopic and theoretical studies are more easily done. In particular, instrumentation recently developed for photo product anion - photoelectron coincidence spectroscopy could provide important information on the energy electrons formed in single photon double electron detachment, ${ }^{32-34}$ although genuine PEPECO experiment would also be highly desirable. ${ }^{4,31}$

Supporting Information. Experimental details, mass spectra with assignments, fitted photodetachhment spectra and linear vs quadratic component of irradiation time plots can be found in the supporting information (PDF). These files are available free of charge.

\section{AUTHOR INFORMATION}

\footnotetext{
*e-mail: rohair@unimelb.edu.au

† e-mail: philippe.dugourd@univ-lyon1.fr
}

\section{ACKNOWLEDGMENT}

R.A.J.O. thanks the Australian Research Council for financial support (DP150101388, and via the ARC CoE for Free Radical Chemistry and Biotechnology, The Universite de Lyon for a visiting Professorship and the School of Chemistry at the University of Melbourne for a short-term study leave. SOLEIL support is acknowledged under project no. 20121299. We also thank the general technical staff of SOLEIL for running the facility, in particular J-F Gil for technical help on DESIRS. The research leading to these results has received funding from the European Research Council under the European Union's Seventh Framework Programme (FP7/2007-2013 Grant agreement N³20659).

(1) Milosavljević, A. R.; Canon, F.; Nicolas, C.; Miron, C.; Nahon, L.; Giuliani, A. Gas-Phase Protein Inner-Shell Spectroscopy by Coupling an Ion Trap with a Soft X-Ray Beamline. J. Phys. Chem. Lett. 2012, 3, 1191-1196.

(2) Vogel, M.; Kasigkeit, C.; Hirsch, K.; Langenberg, A.; Rittmann, J.; Zamudio-Bayer, V.; Kulesza, A.; Mitrić, R.; Möller, T.; v. Issendorff, B.; et al. 2p Core-Level Binding Energies of Size-Selected 
Free Silicon Clusters: Chemical Shifts and Cluster Structure. Phys. Rev. B 2012, 85, 195454.

(3) Lightner, G. S.; Van Brunt, R. J.; Whitehead, W. D. Multiple lonization of Ne, Ar, and Kr Produced by X Rays in the Energy Range 0.28-8.03 keV. Phys. Rev. A 1971, 4, 602-609.

(4) Eland, J. H. D.; Vieuxmaire, O.; Kinugawa, T.; Lablanquie, P.; Hall, R. I.; Penent, F. Complete Two-Electron Spectra in Double Photoionization: The Rare Gases Ar, Kr, and Xe. Phys. Rev. Lett. 2003, 90, 053003.

(5) Mathur, D. Multiply Charged Molecules. Phys. Rep. 1993, 225, 193-272.

(6) Molloy, R. D.; Danielsson, A.; Karlsson, L.; Eland, J. H. D. Double Photoionisation Spectra of Small Molecules and a New Empirical Rule for Double Ionisation Energies. Chem. Phys. 2007, $335,49-54$.

(7) Steger, H.; de Vries, J.; Kamke, B.; Kamke, W.; Drewello, T. Direct Double Ionization of C60 and C70 Fullerenes Using Synchrotron Radiation. Chem. Phys. Lett. 1992, 194, 452-456.

(8) Bilodeau, R. C.; Walter, C. W.; Dumitriu, I.; Gibson, N. D.; Ackerman, G. D.; Bozek, J. D.; Rude, B. S.; Santra, R.; Cederbaum, L. S.; Berrah, N. Photo Double Detachment of CN-: Electronic Decay from an Inner-Valence Hole in Molecular Anions. Chem. Phys. Lett. 2006, 426, 237-241.

(9) Bilodeau, R. C.; Gibson, N. D.; Walter, C. W.; Esteves, D. A.; Phaneuf, R. A.; Schippers, S.; Müller, A.; Aguilar, A.; Hoener, M.; Rost, J. M.; et al. Photo-Multidetachment and Fragmentation of C 60 Anions. J. Phys. Conf. Ser. 2012, 388, 022039.

(10) Bilodeau, R. C.; Gibson, N. D.; Walter, C. W.; Esteves-Macaluso, D. A.; Schippers, S.; Müller, A.; Phaneuf, R. A.; Aguilar, A.; Hoener, M.; Rost, J. M.; et al. Single-Photon Multiple Detachment in Fullerene Negative Ions: Absolute Ionization Cross Sections and the Role of the Extra Electron. Phys. Rev. Lett. 2013, 111, 43003.

(11) Herlert, A.; Schweikhard, L. Two-Electron Emission after Photoexcitation of Metal-Cluster Dianions. New J. Phys. 2012, 14, 055015.

(12) Brunet, C.; Antoine, R.; Dugourd, P.; Duflot, D.; Canon, F.; Giuliani, A.; Nahon, L. Valence Shell Direct Double Photodetachment in Polyanions. New J. Phys. 2013, 15, 063024.

(13) Antoine, R.; Enjalbert, Q.; MacAleese, L.; Dugourd, P.; Giuliani, A.; Nahon, L. Multiple Electron Ejection from Proteins Resulting from Single-Photon Excitation in the Valence Shell. J. Phys. Chem. Lett. 2014, 5, 1666-1671.

(14) Dreuw, A.; Cederbaum, L. S. Multiply Charged Anions in the Gas Phase. Chem. Rev. 2002, 102, 181-200.

(15) Waters, T.; Wang, X.-B.; Wang, L.-S. Electrospray Ionization Photoelectron Spectroscopy: Probing the Electronic Structure of Inorganic Metal Complexes in the Gas-Phase. Coord. Chem. Rev. 2007, 251, 474-491.

(16) Wang, X. B.; Wang, L. S. Photoelectron Spectroscopy of Multiply Charged Anions; Annual Review of Physical Chemistry; Annual Reviews: Palo Alto; 2009.

(17) Wang, X. B.; Wang, L. S. Observation of Negative Electron-Binding Energy in a Molecule. Nature 1999, 400, 245-248.

(18) Wang, X. B.; Ferris, K.; Wang, L. S. Photodetachment of Gaseous Multiply Charged Anions, Copper Phthalocyanine Tetrasulfonate Tetraanion: Tuning Molecular Electronic Energy Levels 
by Charging and Negative Electron Binding. J. Phys. Chem. A 2000, 104, 25-33.

(19) Arnold, K.; Balaban, T. S.; Blom, M. N.; Ehrler, O. T.; Gilb, S.; Hampe, O.; van Lier, J. E.; Weber, J. M.; Kappes, M. M. Electron Autodetachment from Isolated Nickel and Copper Phthalocyanine-Tetrasulfonate Tetraanions: Isomer Specific Rates. J. Phys. Chem. A 2003, 107, 794-803.

(20) Ehrler, O. T.; Yang, J.-P.; Sugiharto, A. B.; Unterreiner, A. N.; Kappes, M. M. Excited State Dynamics of Metastable Phthalocyanine-Tetrasulfonate Tetra-Anions Probed by Pump/probe Photoelectron Spectroscopy. J. Chem. Phys. 2007, 127, 184301.

(21) Daly, S.; Kulesza, A.; Knight, G.; MacAleese, L.; Antoine, R.; Dugourd, P. Visible and Ultraviolet Spectroscopy of Gas Phase Rhodamine 575 Cations. J. Phys. Chem. A 2015, 119, 5634-5641.

(22) Nahon, L.; de Oliveira, N.; Garcia, G. A.; Gil, J. F.; Pilette, B.; Marcouille, O.; Lagarde, B.; Polack, F. DESIRS: A State-of-the-Art VUV Beamline Featuring High Resolution and Variable Polarization for Spectroscopy and Dichroism at SOLEIL. J. Synchrotron Radiat. 2012, 19, 508 520.

(23) Milosavljević, A. R.; Nicolas, C.; Gil, J.-F.; Canon, F.; Réfrégiers, M.; Nahon, L.; Giuliani, A. VUV Synchrotron Radiation: A New Activation Technique for Tandem Mass Spectrometry. J. Synchrotron Radiat. 2012, 19, 174-178.

(24) Kordel, M.; Schooss, D.; Gilb, S.; Blom, M. N.; Hampe, O.; Kappes, M. M. Photodissociation of Trapped Metastable Multiply Charged Anions: A Routine Electronic Spectroscopy of Isolated Large Molecules? J. Phys. Chem. A 2004, 108, 4830-4837.

(25) Brunet, C.; Antoine, R.; Dugourd, P.; Duflot, D.; Canon, F.; Giuliani, A.; Nahon, L. Valence Shell Direct Double Photodetachment in Polyanions. New J. Phys. 2013, 15.

(26) Arnold, K.; Balaban, T. S.; Blom, M. N.; Ehrler, O. T.; Gilb, S.; Hampe, O.; van Lier, J. E.; Weber, J. M.; Kappes, M. M. Electron Autodetachment from Isolated Nickel and Copper Phthalocyanine-Tetrasulfonate Tetraanions: Isomer Specific Rates. J. Phys. Chem. A 2003, $107,794-803$.

(27) Hartman, T.; Juranić, P. N.; Collins, K.; Reilly, B.; Appathurai, N.; Wehlitz, R. Large Molecules Reveal a Linear Length Scaling for Double Photoionization. Phys. Rev. Lett. 2012, 108, 023001.

(28) Alcantara, K. F.; Gomes, A. H. A.; Wolff, W.; Sigaud, L.; Santos, A. C. F. Outer-Shell Double Photoionization of $\mathrm{CH} 2 \mathrm{Cl} 2$. Chem. Phys. 2014, 429, 1-4.

(29) Alcantara, K. F.; Gomes, A. H. A.; Sigaud, L.; Wolf, W.; Santos, A. C. F. Outer-Shell Double Photoionization of $\mathrm{CH} 4$ and $\mathrm{CH} 2 \mathrm{Cl} 2$ Molecules. Phys. Procedia 2015, 66, 2-9.

(30) Pattard, T.; Schneider, T.; Rost, J. M. On the Role of Shake-off in Single-Photon Double Ionization. J. Phys. B At. Mol. Opt. Phys 2003, 189, 189-195.

(31) Hikosaka, Y.; Lablanquie, P.; Penent, F.; Nakano, M.; Ito, K. Multi-Electron Coincidence Spectroscopy: Double Photoionization from Molecular Inner-Shell Orbitals. J. Phys. Conf. Ser. 2014, 488, 012012.

(32) Vonderach, M.; Ehrler, O. T.; Weis, P.; Kappes, M. M. Combining Ion Mobility Spectrometry, Mass Spectrometry, and Photoelectron Spectroscopy in a High-Transmission Instrument. Anal. Chem. 2011, 83, 1108-1115.

(33) Jäger, P.; Brendle, K.; Schwarz, U.; Himmelsbach, M.; Armbruster, M. K.; Fink, K.; Weis, P.; 
Kappes, M. M. Q and Soret Band Photoexcitation of Isolated Palladium Porphyrin Tetraanions Leads to Delayed Emission of Nonthermal Electrons over Microsecond Time Scales. J. Phys. Chem. Lett. 2016, 7, 1167-1172.

(34) Winghart, M.-O.; Yang, J.-P.; Vonderach, M.; Unterreiner, A.-N.; Huang, D.-L.; Wang, L.-S.; Kruppa, S.; Riehn, C.; Kappes, M. M. Time-Resolved Photoelectron Spectroscopy of a Dinuclear Pt(II) Complex: Tunneling Autodetachment from Both Singlet and Triplet Excited States of a Molecular Dianion. J. Chem. Phys. 2016, 144, 054305. 


\section{Supplementary Material}

\section{Single-Photon, Double Photodetachment of Nickel}

\section{Phthalocyanine Tetrasulfonic Acid 4- Anions.}

Steven Daly, ${ }^{\mathrm{a}}$ Marion Girod, ${ }^{\mathrm{b}}$ Marin Vojkovic, ${ }^{\mathrm{a}}$ Alexandre Giuliani, ${ }^{\mathrm{c}, \mathrm{d}}$ Rodolphe Antoine, ${ }^{\mathrm{a}}$

Laurent Nahon, ${ }^{\mathrm{c}}$ Richard A. J. O'Hair ${ }^{*}, \mathrm{f}$ and Philippe Dugourd, ${ }^{\text {a }}$

${ }^{a}$ Institut Lumière Matière, Université Claude Bernard Lyon 1, CNRS UMR 5306, Lyon, France. E-mail: philippe.dugourd@univ-lyon1.fr

${ }^{\mathrm{b}}$ Institut des Sciences Analytiques, Université de Lyon, Université Claude Bernard Lyon 1, CNRS \& ENS Lyon, UMR 5280, 69100 Villeurbanne, France.

${ }^{\mathrm{c}}$ SOLEIL, l'Orme des Merisiers, St Aubin, BP48, F-91192 Gif sur Yvette Cedex, France

${ }^{\mathrm{d}}$ INRA, UAR1008 Caractérisation et Élaboration des Produits Issus de l'Agriculture, F-44316 Nantes, France

${ }^{\mathrm{e}}$ School of Chemistry and Bio21 Molecular Science and Biotechnology Institute, University of Melbourne, 30 Flemington Rd, Parkville, Victoria 3010, Australia. E-mail: rohair@unimelb.edu.au ${ }^{\mathrm{f}}$ ARC Centre of Excellence for Free Radical Chemistry and Biotechnology. 
Materials: Chemicals from the following suppliers were used without further purification: (i) nickel phthalocyanine tetrasulfonic acid tetrasodium salt, NiPc, was purchased form SigmaAldrich (Saint Quentin Fallavier, France); (ii) methanol was HPLC grade sourced from Fisher Chemical (Fisher Scientific, UK); (iii) Milli-Q water (18.2 M $\Omega . c m$; Millipore Corporation Billerica, MA, USA) was used.

\section{Mass spectrometry:}

Water solutions of NiPc $(0.8 \mathrm{mg} / \mathrm{mL})$ were further diluted with methanol:water 50:50 $(\% \mathrm{v} / \mathrm{v})$ to a concentration of around $40 \mu \mathrm{M}$ and introduced into modified quadrupole linear ion trap mass spectrometers (LTQ, Thermo Fisher Scientific, San Jose, CA, USA) via electrospray ionization (ESI) using a syringe pump set to a flow rate of $5 \mu \mathrm{L} \cdot \mathrm{min}^{-1}$. The typical ESI conditions used were: spray voltage, $-5.0 \mathrm{kV}$, capillary temperature, $150^{\circ} \mathrm{C}$, nitrogen sheath gas pressure, 10 (arbitrary units), capillary voltage $-2 \mathrm{~V}$. $\mathrm{NiPc}^{3-\bullet}$ were formed via collision induced electron detachment from mass selected $\mathrm{NiPc}^{4-}$ for an activation time of $30 \mathrm{~ms}$ with a normalized collision energy set to $15 \%$. The mass selected $\mathrm{NiPc}^{4-}$ and $\mathrm{NiPc}^{3-\cdot}$ were subjected to irradiation in two different modified mass spectrometers, discussed separately below.

\section{Spectroscopy over range of 6 to $16 \mathrm{eV}$ :}

VUV experiments were carried out on a Thermo LTQ linear ion trap mass spectrometer that has been coupled to the undulator based DESIRS beamline of the SOLEIL synchrotron ${ }^{1,2}$. Two different methods were employed to ensure the suppression of higher harmonics of the undulator. Between $5-8 \mathrm{eV}$ a MgF window was inserted just before the ion trap; for photon energies higher than $8 \mathrm{eV}$, a gas filter ${ }^{3}$ filled with 0.25 mbar argon was used. A $5.57 \mathrm{~m}$ normal incidence monochromator with a $200 \mathrm{gr} / \mathrm{mm}$ grating was used, providing a bandwidth of approximately $30 \mathrm{meV}$ at $12 \mathrm{eV}$ and a photon flux of the order $10^{13}$ photons per second. For all photon energies the entrance and exit slits to the monochromator were set to 200 and 400 $\mu \mathrm{m}$ respectively. The action spectrum was performed in two scans defined by the regimes for 
suppression of the higher order light given above. In the $5-8 \mathrm{eV}$ region, an irradiation time of $200 \mathrm{~ms}$ and acquisition time of 4 minutes per wavelength were used for both 4- and 3-•. In the $8-16 \mathrm{eV}$ region the irradiation time was reduced to $150 \mathrm{~ms}$ due to the greater photon flux from the undulator and increased cross-section and the acquisition time reduced to 90 seconds per photon energy.

\section{Spectroscopy over range of 1.8 to $5.5 \mathrm{eV}$ :}

The experimental setup used to perform the experiments presented in this paper has been described in detail previously ${ }^{4}$. Briefly, a linear quadrupole ion trap mass spectrometer (LTQ Velos, Thermo Fisher Scientific, San Jose, CA) was used to generate, mass select, and trap ions in a first, high pressure trap for a controlled period during which time they may be activated by laser irradiation (LID). Fragment ions are subsequently transmitted to a second, lower pressure ion trap, and are mass analyzed. A fused silica window ( $3 \mathrm{~mm}$ thick, 1 in. diameter) is positioned at the back end of the instrument, and 1-2 $\mathrm{mm}$ diameter circular openings in the trapping electrodes allow coupling of light source and trapped ions. In order to optimize laser transmission, the central hole of the electrode closest to the fused silica window was enlarged to $5 \mathrm{~mm}$ in diameter.

The light source used was a Horizon OPO pumped by the third harmonic of a Surelite II Nd:YAG laser (Continuum, Santa Clara, CA). A repetition rate of $10 \mathrm{~Hz}$ and a pulse width of $5 \mathrm{~ns}$ were used. The beam was focused into the first ion trap using a 1,000 mm focal length convergent lens. A mechanical shutter, synchronized with the mass spectrometer, was used to stop the beam at all times except the "ion activation window", that is, the time after ion accumulation and before the mass analysis. A single laser pulse was used for the irradiation of the trapped ions, and when irradiating ions the normalized collision energy is kept at zero.

To record action spectra, the laser wavelength was scanned between 700 and $420 \mathrm{~nm}$, and between 399 and $235 \mathrm{~nm}$, in $0.03 \mathrm{~nm}$ steps and with a $1 \mathrm{~s}$ dwell time at each wavelength. 
Mass spectra were recorded every $9 \mu$ scans, which corresponded on average to one mass spectrum per second. Laser power was recorded by performing a second scan under identical conditions immediately following acquisition of the action spectrum.

\section{Data analysis:}

To analyze the UV-Vis data, each mass spectrum was assigned a wavelength value given by

$$
\lambda_{\text {start }}-\left((i-1) *\left(\frac{\Delta \lambda}{n}\right)\right)
$$

where $\lambda_{\text {start }}$ is the starting wavelength of the scan, $i$ the mass spectrum number, $\Delta \lambda$ is the total wavelength change during the scan, and $n$ the total number of mass spectra acquired during the acquisition. The same procedure was used to provide a wavelength range for the laser power $(P)$, and a linear interpolation performed to give values of the laser power at the wavelengths assigned to each mass spectrum. For the VUV data, a fixed photon energy is used for each mass spectrum, so the wavelength is explicitly known. A flux-normalized yield of photo-detachment is deduced from the mass spectrum through:

$$
\left(I_{P D} / I_{\text {total }}\right) / \phi
$$

Where $I_{P D}$ is the intensity of the photodetached species, $I_{\text {total }}$ is the total intensity, and $\phi$ is the photon flux which is directly measured by a photodiode in the VUV and is given by $\lambda * P$ where $P$ is the laser power in the UV-Vis. Double photo-detachment yield is deduced from the mass spectrum through:

$$
\left(I_{2 P D} / I_{\text {total }}\right) / \phi
$$

Where $I_{2 P D}$ is the intensity of the double photodetached species.

(1) Nahon, L.; de Oliveira, N.; Garcia, G. A.; Gil, J. F.; Pilette, B.; Marcouille, O.; Lagarde, B.; Polack, F. DESIRS: A State-of-the-Art VUV Beamline Featuring High Resolution and Variable Polarization for Spectroscopy and Dichroism at SOLEIL. $J$. Synchrotron Radiat. 2012, 19, 508-520. 
(2) Milosavljević, A. R.; Nicolas, C.; Gil, J.-F.; Canon, F.; Réfrégiers, M.; Nahon, L.; Giuliani, A. VUV Synchrotron Radiation: A New Activation Technique for Tandem Mass Spectrometry. J. Synchrotron Radiat. 2012, 19, 174-178.

(3) Mercier, B.; Compin, M.; Prevost, C.; Bellec, G.; Thissen, R.; Dutuit, O.; Nahon, L. Experimental and Theoretical Study of a Differentially Pumped Absorption Gas Cell Used as a Low Energy-Pass Filter in the Vacuum Ultraviolet Photon Energy Range. $J$. Vac. Sci. Technol. a-Vacuum Surfaces Film. 2000, 18, 2533-2541.

(4) Daly, S.; Kulesza, A.; Knight, G.; MacAleese, L.; Antoine, R.; Dugourd, P. Visible and Ultraviolet Spectroscopy of Gas Phase Rhodamine 575 Cations. J. Phys. Chem. A 2015, 119, 5634-5641. 

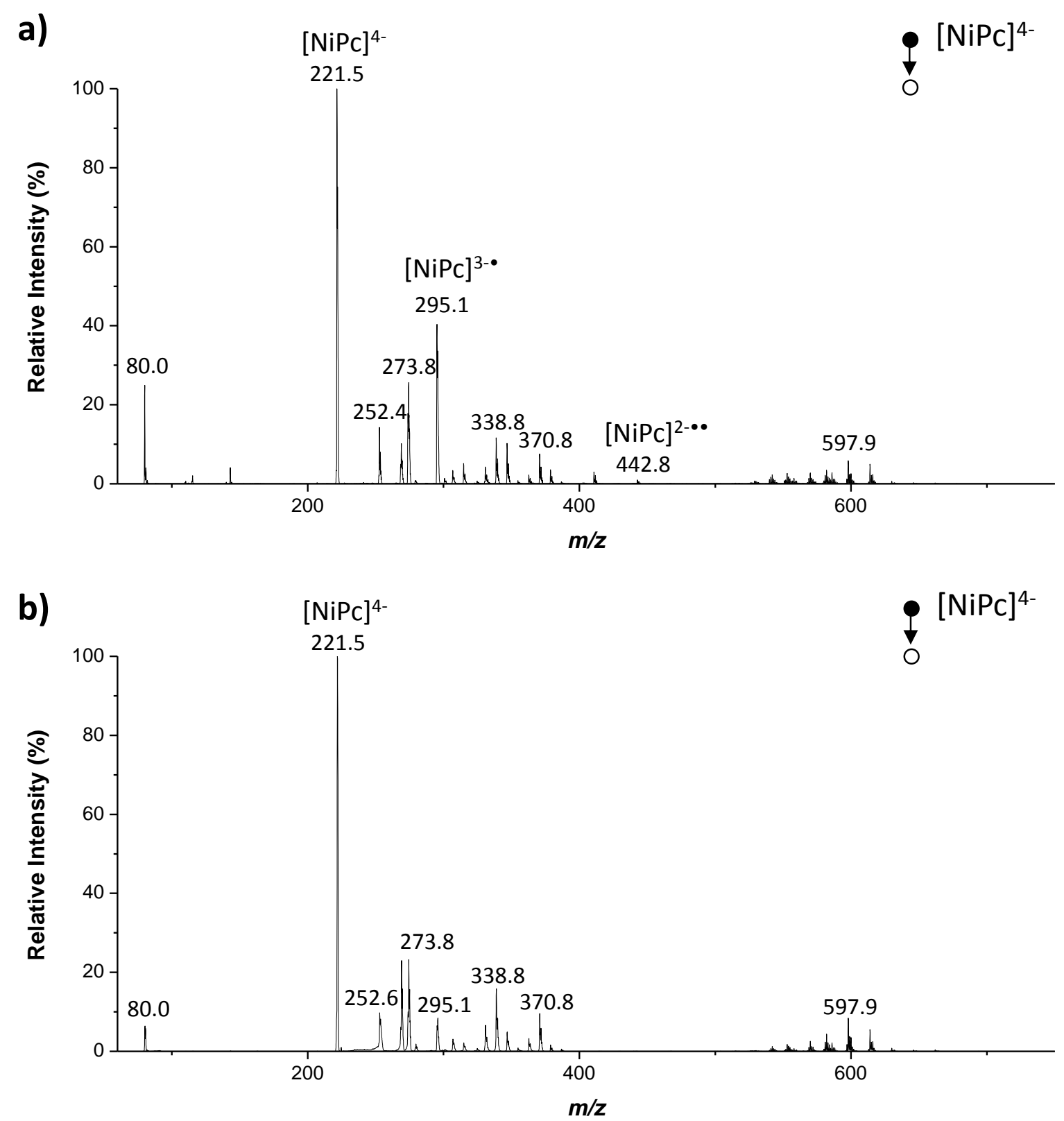

Figure S1. LID spectrum of $\left[\mathrm{NiPc}^{4-}\right.$ ion $(\mathrm{m} / \mathrm{z} 221.5)$ at a) $5.28 \mathrm{eV}$ and b) $1.88 \mathrm{eV}$. Activation time $100 \mathrm{~ms}$. 


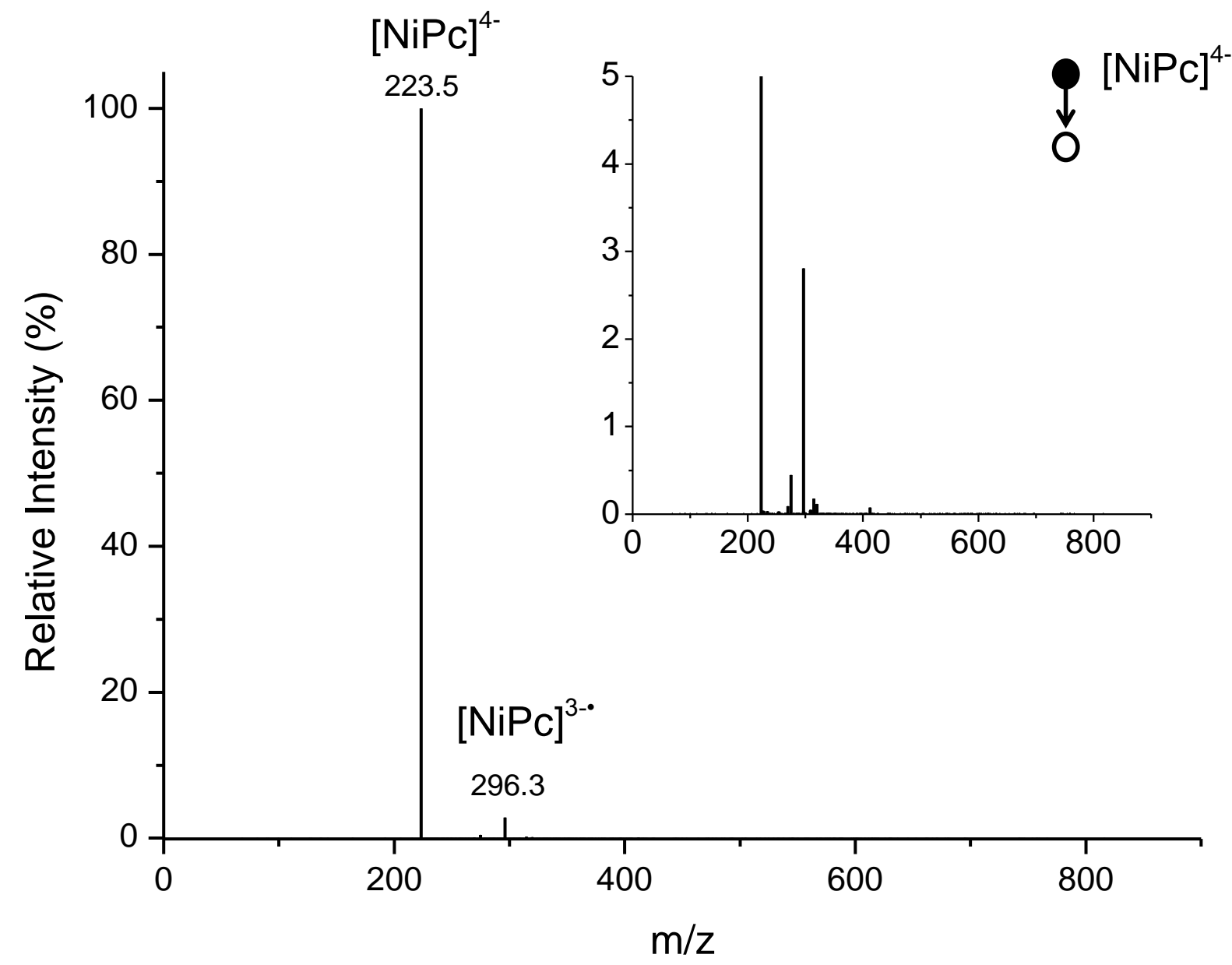

Figure S2. LID spectrum of $[\mathrm{NiPc}]^{4-}$ ion $(\mathrm{m} / \mathrm{z} 223.5)$ at a) $15 \mathrm{eV}$. Activation time $150 \mathrm{~ms}$. 

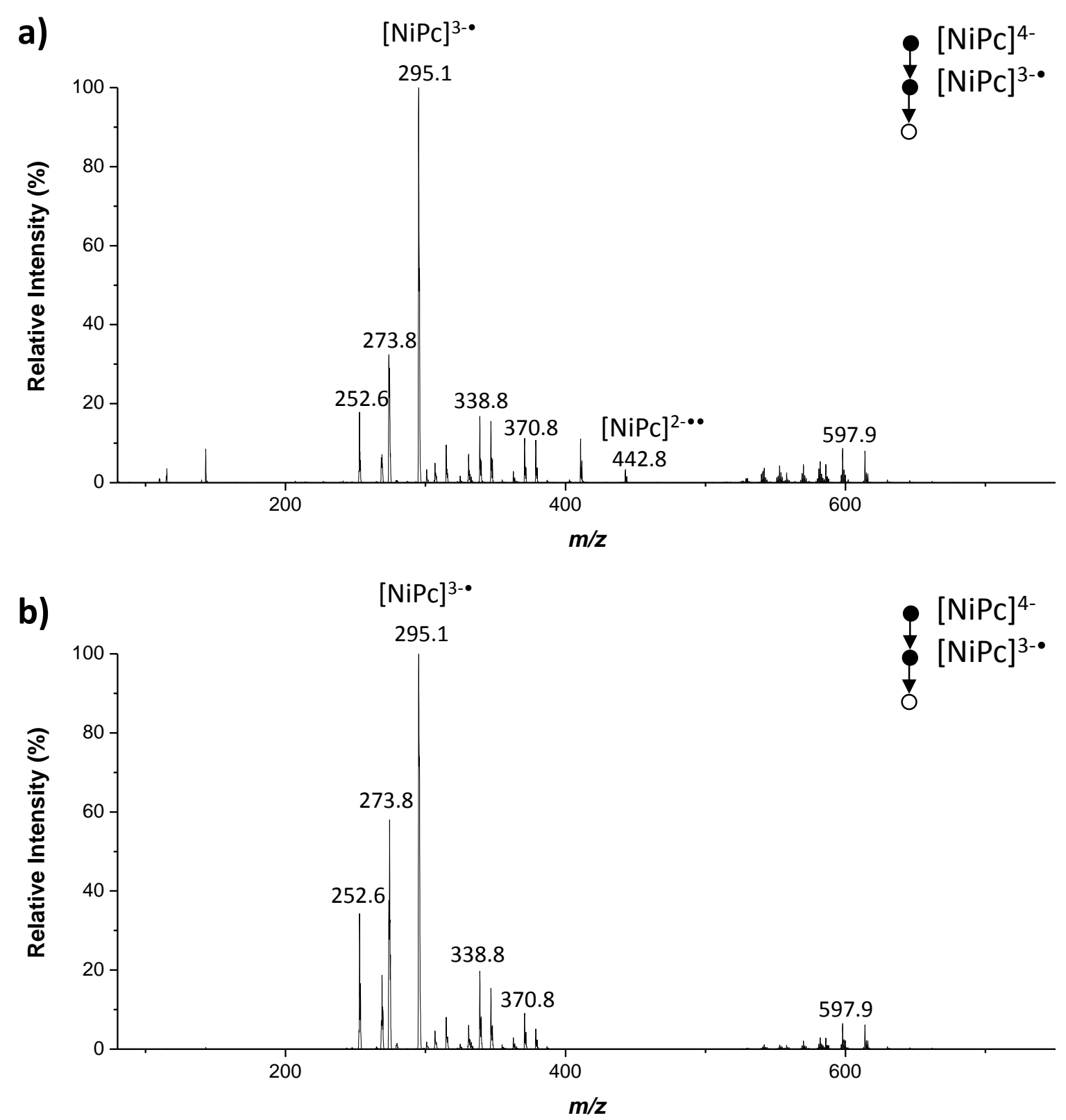

Figure S3. LID spectrum of $[\mathrm{NiPc}]^{3-\bullet}$ ion $(\mathrm{m} / \mathrm{z} 295.1)$ at a) $5.28 \mathrm{eV}$ and b) $1.88 \mathrm{eV}$. Activation time $100 \mathrm{~ms}$. 


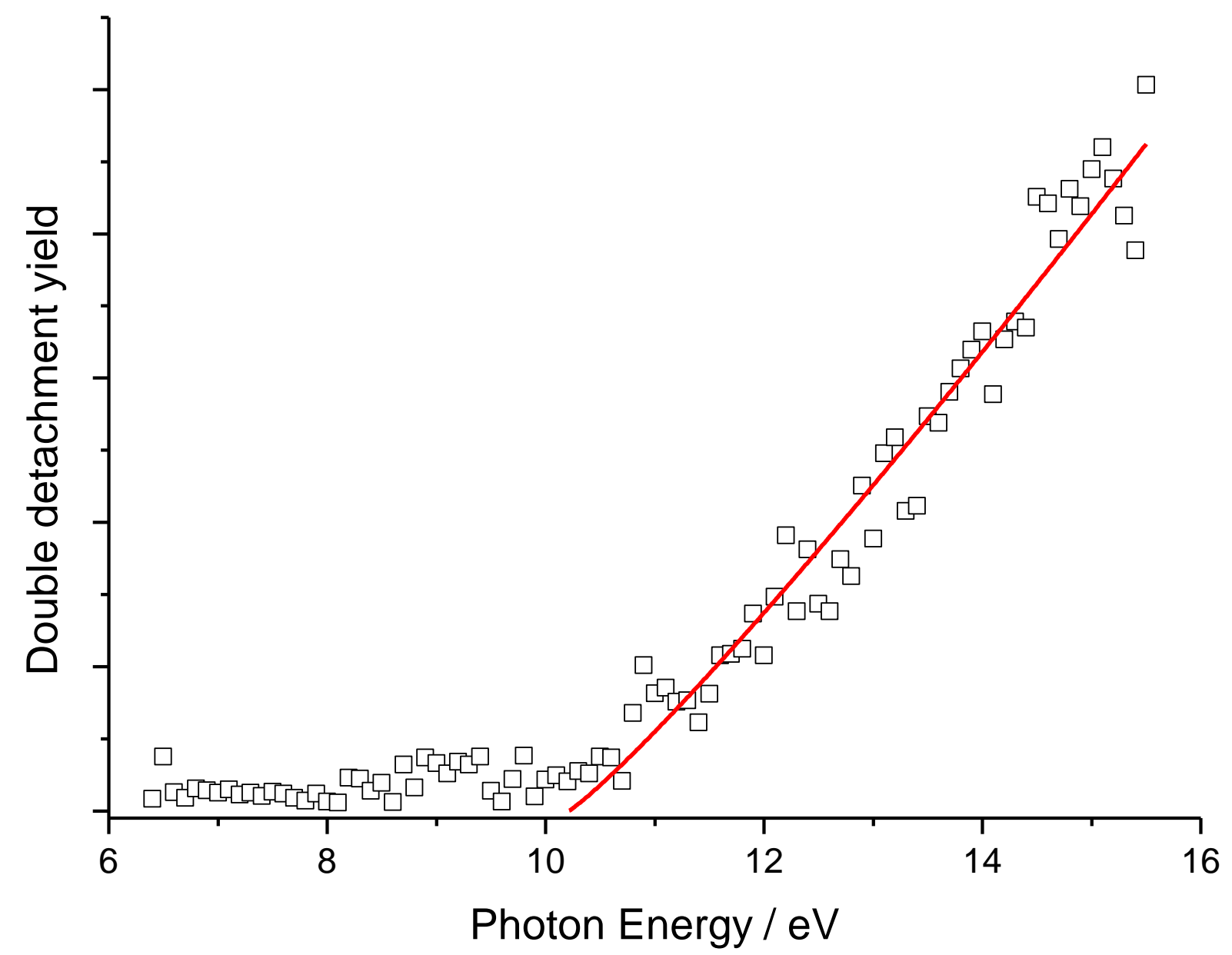

Figure S4. Wannier-type fit to the onset of double photodetachment of $[\mathrm{NiPc}]^{4-}$. 


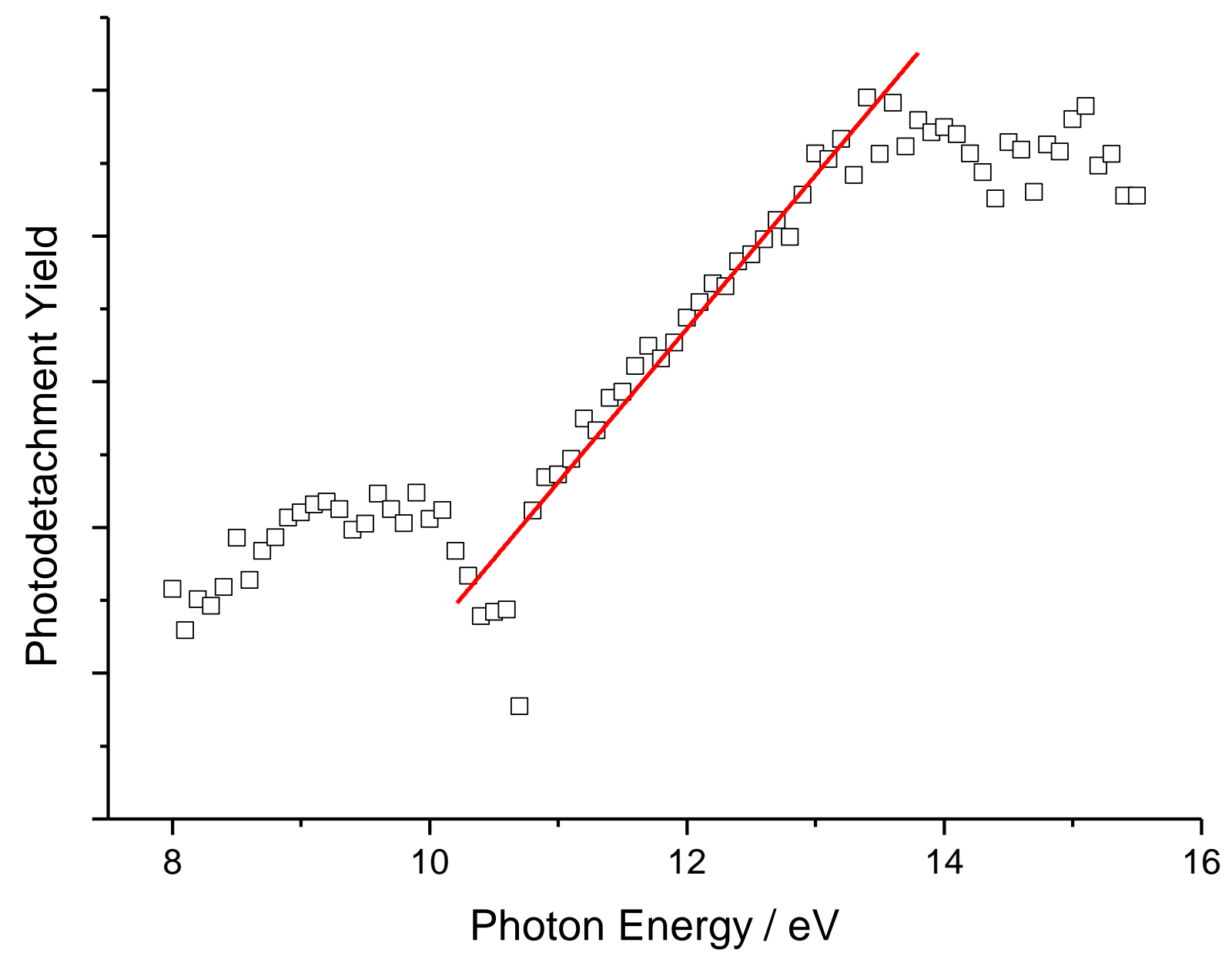

Figure S5. Linear fit for the VUV onset of photodetachment of $[\mathrm{NiPc}]^{4-}$ to the baseline. Since thermal electron loss is observed from $[\mathrm{NiPc}]^{4-}-$ which is metastable - there is a raised and relatively noisy baseline. This precludes the use of the Wannier-type onset fit which is used in Figures S4 and S7. 


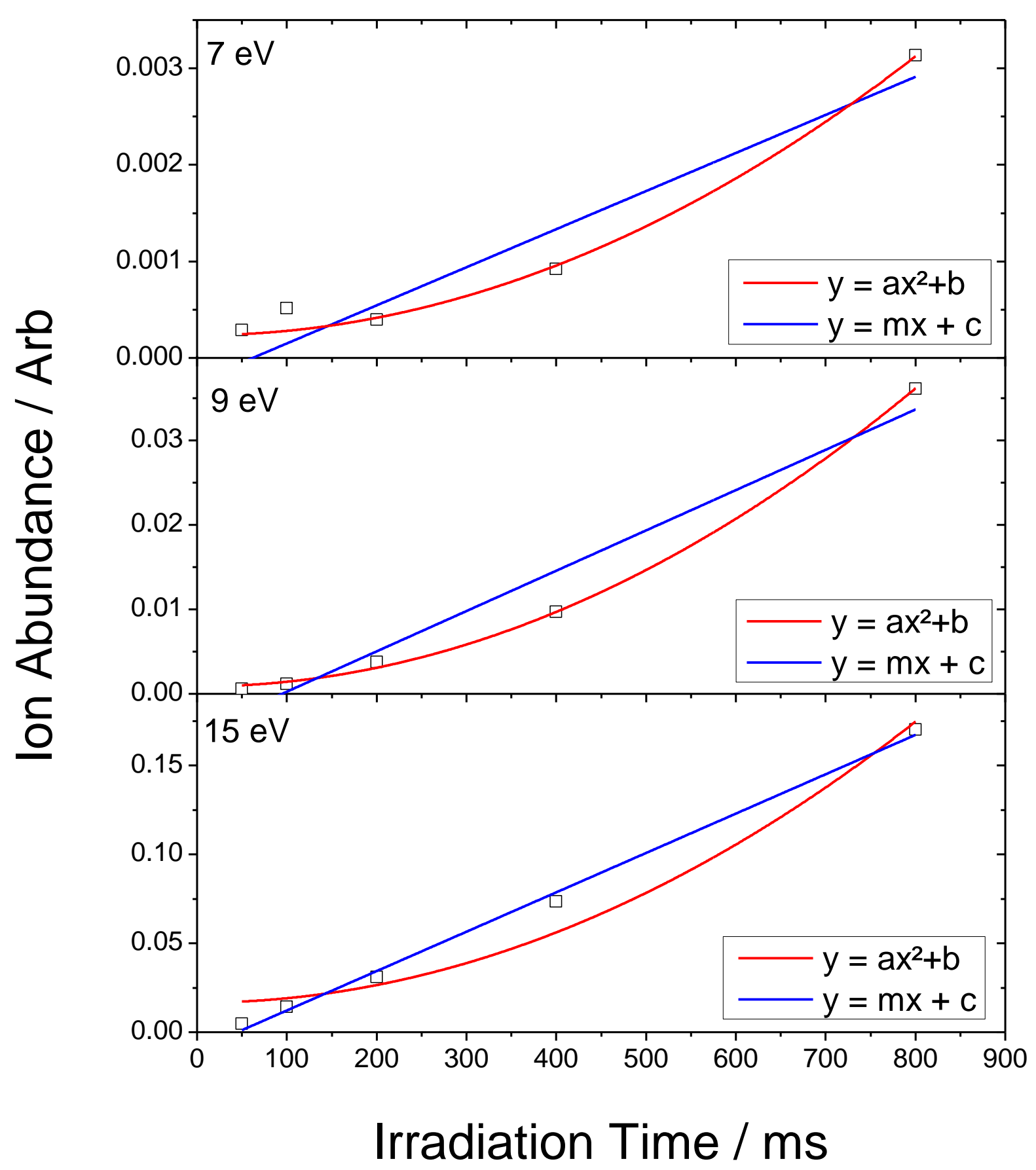

Figure S6. Fitting of the ion abundance as a function of irradiation time using either purely linear (blue) or purely quadratic (red) functions. At 7 and $9 \mathrm{eV}$ the ion abundance clearly has a quadratic dependence on the irradiation time, whilst at $15 \mathrm{eV}$ linear is clearly dominant (although a quadratic component is still present). 


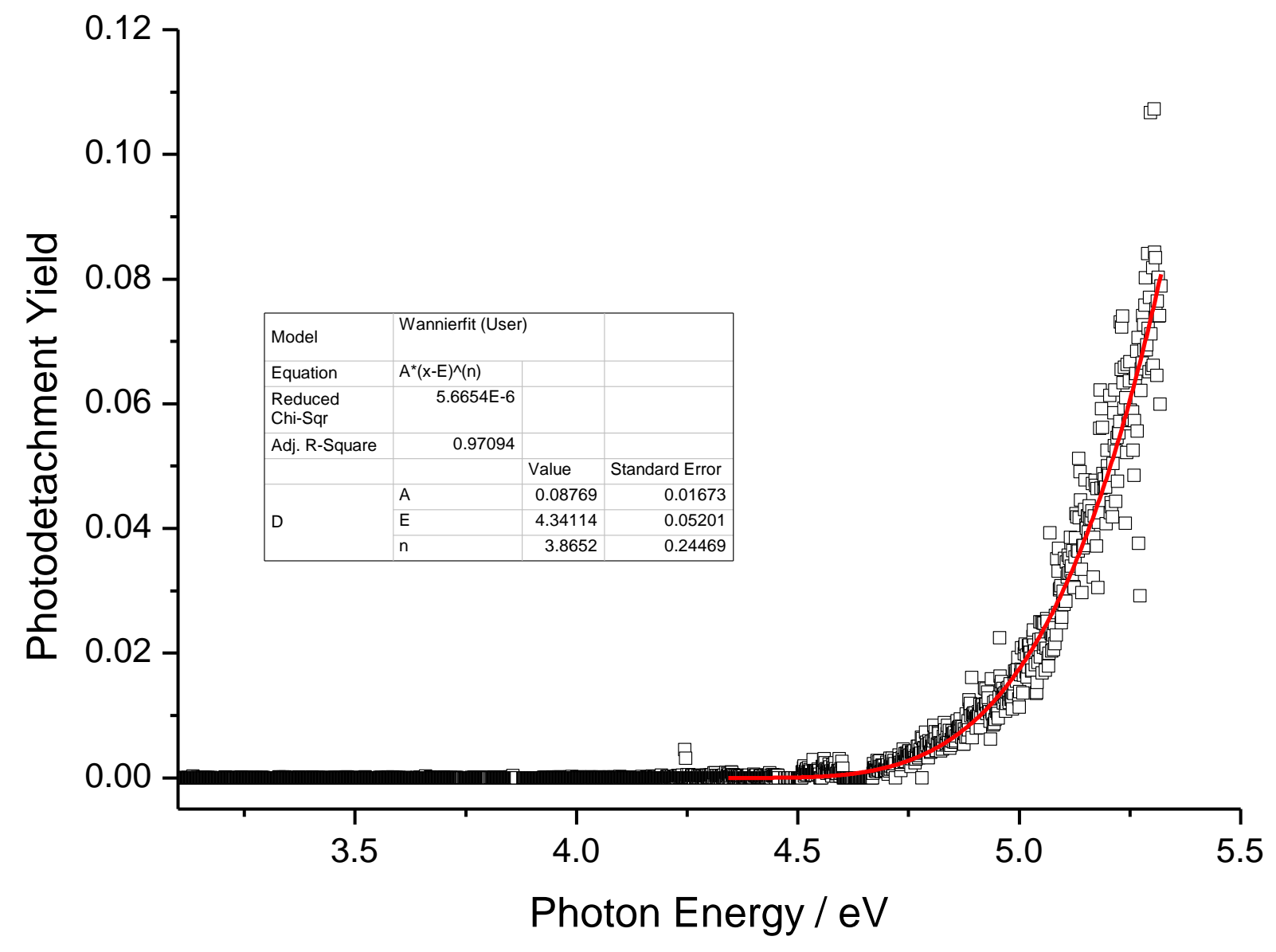

Figure S7. Wannier-type fit to the onset of photodetachment of $[\mathrm{NiPc}]^{3-\bullet}$.

Table S1. Summary of product ions observed upon irradiation of [NiPc] ${ }^{4-}$ ion at $m / z 221.5$.

\begin{tabular}{|c|c|c|}
\hline$m / z$ & Assignment & Losses \\
\hline
\end{tabular}




\begin{tabular}{|c|c|c|}
\hline 80.0 & $\mathrm{SO}_{3}^{-{ }^{-}}$ & {$\left[\mathrm{NiPc}-\mathrm{SO}_{3}\right]^{3 \cdot-}$} \\
\hline 110.3 & {$\left[\mathrm{Ni}+2 \mathrm{SO}_{3}+\mathrm{SO}_{2}+\mathrm{SOH}\right]^{3}$} & \\
\hline 115.3 & {$\left[\mathrm{Ni}+2 \mathrm{SO}_{3}+2 \mathrm{SO}_{2}\right]^{3-\bullet}$} & \\
\hline 143.0 & {$\left[\mathrm{C}_{6} \mathrm{H}_{5}+\mathrm{SO}_{2} \mathrm{H}_{2}\right]^{-}$} & \\
\hline 221.5 & {$[\mathrm{NiPc}]^{4-}$} & \\
\hline 252.4 & {$\left[\mathrm{NiPc}-2 \mathrm{SO}_{2}\right]^{3-\bullet}$} & $1 \mathrm{e}-$ and $2 \mathrm{SO}_{2}$ \\
\hline 268.6 & {$\left[\mathrm{NiPc}-\mathrm{SO}_{3}\right]^{3-\bullet}$} & $1 \mathrm{e}-$ and $\mathrm{SO}_{3}$ \\
\hline 273.8 & {$\left[\mathrm{NiPc}-\mathrm{SO}_{2}\right]^{3-\bullet}$} & $1 \mathrm{e}-$ and $\mathrm{SO}_{2}$ \\
\hline 295.1 & {$[\mathrm{NiPc}]^{3-\bullet}$} & $1 \mathrm{e}-$ \\
\hline 298.8 & {$\left[\mathrm{NiPc}-2 \mathrm{SO}_{2}-2 \mathrm{SO}_{3}\right]^{2-*}$} & $2 \mathrm{e}-; 2 \mathrm{SO}_{2}$ and $2 \mathrm{SO}_{3}$ \\
\hline 306.8 & {$\left[\mathrm{NiPc}-3 \mathrm{SO}_{2}-\mathrm{SO}_{3}\right]^{2-\cdots}$} & $2 \mathrm{e}-; 3 \mathrm{SO}_{2}$ and $\mathrm{SO}_{3}$ \\
\hline 314.8 & {$\left[\mathrm{NiPc}-4 \mathrm{SO}_{2}\right]^{2 \cdots}$} & $2 \mathrm{e}-$ and $4 \mathrm{SO}_{2}$ \\
\hline 322.8 & {$\left[\mathrm{NiPc}-3 \mathrm{SO}_{3}\right]^{2-\bullet}$} & $2 \mathrm{e}-$ and $3 \mathrm{SO}_{3}$ \\
\hline 330.8 & {$\left[\mathrm{NiPc}-\mathrm{SO}_{2}-2 \mathrm{SO}_{3}\right]^{2-\bullet \cdot}$} & $2 \mathrm{e}-; \mathrm{SO}_{2}$ and $2 \mathrm{SO}_{3}$ \\
\hline 338.8 & {$\left[\mathrm{NiPc}-2 \mathrm{SO}_{2}-\mathrm{SO}_{3}\right]^{2 \cdots-\bullet}$} & $2 \mathrm{e}-; 2 \mathrm{SO}_{2}$ and $\mathrm{SO}_{3}$ \\
\hline 346.8 & {$\left[\mathrm{NiPc}-3 \mathrm{SO}_{2}\right]^{2-\bullet}$} & $2 \mathrm{e}-$ and $3 \mathrm{SO}_{2}$ \\
\hline 354.8 & {$\left[\mathrm{NiPc}-2 \mathrm{SO}_{2}-\mathrm{SO}\right]^{2-*}$} & $2 \mathrm{e}-; 2 \mathrm{SO}_{2}$ and $\mathrm{SO}$ \\
\hline 362.8 & {$\left[\mathrm{NiPc}-2 \mathrm{SO}_{3}\right]^{2-\cdot \cdot}$} & $2 \mathrm{e}-$ and $2 \mathrm{SO}_{3}$ \\
\hline 370.8 & {$\left[\mathrm{NiPc}-\mathrm{SO}_{2}-\mathrm{SO}_{3}\right]^{2-\bullet}$} & $2 \mathrm{e}-; \mathrm{SO}_{2}$ and $\mathrm{SO}_{3}$ \\
\hline 378.8 & {$\left[\mathrm{NiPc}-2 \mathrm{SO}_{2}\right]^{2-\bullet}$} & $2 \mathrm{e}-$ and $2 \mathrm{SO}_{2}$ \\
\hline 386.8 & {$\left[\mathrm{NiPc}-\mathrm{SO}_{2}-\mathrm{SO}\right]^{2 \cdots}$} & $2 \mathrm{e}-; \mathrm{SO}_{2}$ and $\mathrm{SO}$ \\
\hline 402.8 & {$\left[\mathrm{NiPc}-\mathrm{SO}_{3}\right]^{2-*}$} & $2 \mathrm{e}-$ and $\mathrm{SO}_{3}$ \\
\hline 410.8 & {$\left[\mathrm{NiPc}-\mathrm{SO}_{2}\right]^{2-\bullet}$} & $2 \mathrm{e}-$ and $\mathrm{SO}_{2}$ \\
\hline 442.8 & {$[\mathrm{NiPc}]^{2-\bullet}$} & $2 \mathrm{e}-$ \\
\hline 565.9 & {$\left[\mathrm{NiPc}-4 \mathrm{SO}_{3}\right]^{1 \cdots \cdots}$} & $3 \mathrm{e}-$ and $4 \mathrm{SO}_{3}$ \\
\hline 581.9 & {$\left[\mathrm{NiPc}-\mathrm{SO}_{2}-3 \mathrm{SO}_{3}\right]^{1-\cdots}$} & $3 \mathrm{e}-; \mathrm{SO}_{2}$ and $3 \mathrm{SO}_{3}$ \\
\hline 597.9 & {$\left[\mathrm{NiPc}-2 \mathrm{SO}_{2}-2 \mathrm{SO}_{3}\right]^{1-\cdots}$} & $3 \mathrm{e}-; 2 \mathrm{SO}_{2}$ and $2 \mathrm{SO}_{3}$ \\
\hline 613.9 & {$\left[\mathrm{NiPc}-3 \mathrm{SO}_{2}-\mathrm{SO}_{3}\right]^{1-\cdots \cdots}$} & $3 \mathrm{e}-; 3 \mathrm{SO}_{2}$ and $\mathrm{SO}_{3}$ \\
\hline 629.9 & {$\left[\mathrm{NiPc}-4 \mathrm{SO}_{2}\right]^{1-\cdots}$} & $3 \mathrm{e}-$ and $4 \mathrm{SO}_{2}$ \\
\hline 645.9 & {$\left[\mathrm{NiPc}-3 \mathrm{SO}_{2}-\mathrm{SO}\right]^{1-\cdots}$} & $3 \mathrm{e}-; 3 \mathrm{SO}_{2}$ and $\mathrm{SO}$ \\
\hline 661.9 & {$\left[\mathrm{NiPc}-3 \mathrm{SO}_{3}\right]^{1-\cdots}$} & $3 \mathrm{e}-$ and $3 \mathrm{SO}_{3}$ \\
\hline
\end{tabular}


Table S2. Summary of product ions observed upon irradiation of $[\mathrm{NiPc}]^{3-\bullet}$ ion at $\mathrm{m} / z 295.1$.

\begin{tabular}{|c|c|c|}
\hline$m / z$ & Assignment & Losses \\
\hline 110.3 & {$\left[\mathrm{Ni}+2 \mathrm{SO}_{3}+\mathrm{SO}_{2}+\mathrm{SOH}\right]^{3-}$} & \\
\hline 115.3 & {$\left[\mathrm{Ni}+2 \mathrm{SO}_{3}+2 \mathrm{SO}_{2}\right]^{3-\bullet}$} & \\
\hline 143.0 & {$\left[\mathrm{C}_{6} \mathrm{H}_{5}+\mathrm{SO}_{2} \mathrm{H}_{2}\right]^{-}$} & \\
\hline 252.6 & {$\left[\mathrm{NiPc}-2 \mathrm{SO}_{2}\right]^{3-\bullet}$} & $2 \mathrm{SO}_{2}$ \\
\hline 268.6 & {$\left[\mathrm{NiPc}-\mathrm{SO}_{3}\right]^{3-\bullet}$} & $\mathrm{SO}_{3}$ \\
\hline 273.8 & {$\left[\mathrm{NiPc}-\mathrm{SO}_{2}\right]^{3-\bullet}$} & $\mathrm{SO}_{2}$ \\
\hline 295.1 & {$[\mathrm{NiPc}]^{3-\bullet}$} & \\
\hline 298.8 & {$\left[\mathrm{NiPc}-2 \mathrm{SO}_{2}-2 \mathrm{SO}_{3}\right]^{2-\bullet}$} & $1 \mathrm{e}-; 2 \mathrm{SO}_{2}$ and $2 \mathrm{SO}_{3}$ \\
\hline 306.8 & {$\left[\mathrm{NiPc}-3 \mathrm{SO}_{2}-\mathrm{SO}_{3}\right]^{2-\cdots}$} & $1 \mathrm{e}-; 3 \mathrm{SO}_{2}$ and $\mathrm{SO}_{3}$ \\
\hline 314.8 & {$\left[\mathrm{NiPc}-4 \mathrm{SO}_{2}\right]^{2-\bullet}$} & $1 \mathrm{e}-$ and $4 \mathrm{SO}_{2}$ \\
\hline 322.8 & {$\left[\mathrm{NiPc}-3 \mathrm{SO}_{3}\right]^{2-\cdots}$} & $1 \mathrm{e}-$ and $3 \mathrm{SO}_{3}$ \\
\hline 330.8 & {$\left[\mathrm{NiPc}-\mathrm{SO}_{2}-2 \mathrm{SO}_{3}\right]^{2-\cdots}$} & $1 \mathrm{e}-; \mathrm{SO}_{2}$ and $2 \mathrm{SO}_{3}$ \\
\hline 338.8 & {$\left[\mathrm{NiPc}-2 \mathrm{SO}_{2}-\mathrm{SO}_{3}\right]^{2-\bullet \cdot}$} & $1 \mathrm{e}-; 2 \mathrm{SO}_{2}$ and $\mathrm{SO}_{3}$ \\
\hline 346.8 & {$\left[\mathrm{NiPc}-3 \mathrm{SO}_{2}\right]^{2-\bullet}$} & $1 \mathrm{e}-$ and $3 \mathrm{SO}_{2}$ \\
\hline 354.8 & {$\left[\mathrm{NiPc}-2 \mathrm{SO}_{2}-\mathrm{SO}\right]^{2-\bullet}$} & $1 \mathrm{e}-; 2 \mathrm{SO}_{2}$ and $\mathrm{SO}$ \\
\hline 362.8 & {$\left[\mathrm{NiPc}-2 \mathrm{SO}_{3}\right]^{2-* \bullet}$} & $1 \mathrm{e}-$ and $2 \mathrm{SO}_{3}$ \\
\hline 370.8 & {$\left[\mathrm{NiPc}-\mathrm{SO}_{2}-\mathrm{SO}_{3}\right]^{2-\bullet \cdot}$} & $1 \mathrm{e}-; \mathrm{SO}_{2}$ and $\mathrm{SO}_{3}$ \\
\hline 378.8 & {$\left[\mathrm{NiPc}-2 \mathrm{SO}_{2}\right]^{2-\bullet}$} & $1 \mathrm{e}-$ and $2 \mathrm{SO}_{2}$ \\
\hline 386.8 & {$\left[\mathrm{NiPc}-\mathrm{SO}_{2}-\mathrm{SO}\right]^{2-\bullet \bullet}$} & $1 \mathrm{e}-; \mathrm{SO}_{2}$ and $\mathrm{SO}$ \\
\hline
\end{tabular}




\begin{tabular}{|c|c|c|}
\hline 402.8 & {$\left[\mathrm{NiPc}-\mathrm{SO}_{3}\right]^{2-\cdots}$} & $1 \mathrm{e}-$ and $\mathrm{SO}_{3}$ \\
\hline 410.8 & {$\left[\mathrm{NiPc}-\mathrm{SO}_{2}\right]^{2-\cdots}$} & $1 \mathrm{e}-$ and $\mathrm{SO}_{2}$ \\
\hline 442.8 & {$[\mathrm{NiPc}]^{2-\cdots}$} & 1 e- \\
\hline 565.9 & {$\left[\mathrm{NiPc}-4 \mathrm{SO}_{3}\right]^{1-\cdots}$} & 2 e- and $4 \mathrm{SO}_{3}$ \\
\hline 581.9 & {$\left[\mathrm{NiPc}-\mathrm{SO}_{2}-3 \mathrm{SO}_{3}\right]^{1-\cdots}$} & 2 e- $; \mathrm{SO}_{2}$ and $3 \mathrm{SO}_{3}$ \\
\hline 597.9 & {$\left[\mathrm{NiPc}-2 \mathrm{SO}_{2}-2 \mathrm{SO}_{3}\right]^{1-\cdots}$} & 2 e- $; 2 \mathrm{SO}_{2}$ and $2 \mathrm{SO}_{3}$ \\
\hline 613.9 & {$\left[\mathrm{NiPc}-3 \mathrm{SO}_{2}-\mathrm{SO}_{3}\right]^{1-\cdots}$} & 2 e- $; 3 \mathrm{SO}_{2}$ and $\mathrm{SO}_{3}$ \\
\hline 629.9 & {$\left[\mathrm{NiPc}-4 \mathrm{SO}_{2}\right]^{1-\cdots}$} & 2 e- and $4 \mathrm{SO}_{2}$ \\
\hline 645.9 & {$\left[\mathrm{NiPc}-3 \mathrm{SO}_{2}-\mathrm{SO}^{1-\cdots \cdots}\right.$} & $2 \mathrm{e}-; 3 \mathrm{SO}_{2}$ and $\mathrm{SO}^{1-\cdots}$ \\
\hline 661.9 & {$\left[\mathrm{NiPc}-3 \mathrm{SO}_{3}\right]^{1-\cdots}$} & 2 e- and $3 \mathrm{SO}_{3}$ \\
\hline
\end{tabular}

